\title{
Winterlichter 2019 im Palmengarten
}

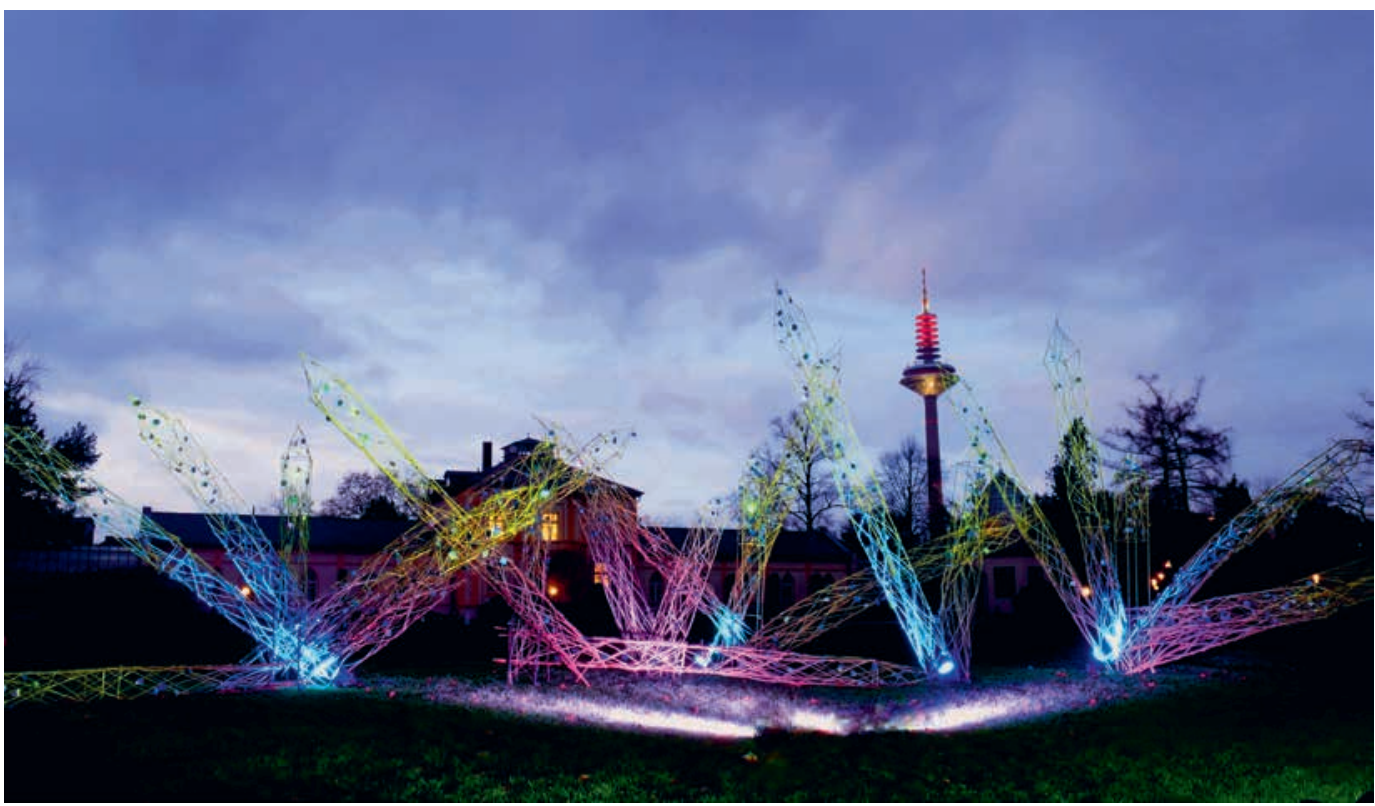

Abb. 1: Eine Kristallgruppe aus Bambusstäben und Weidenruten auf der Spielwiese. (Foto: H. STEINECKE)

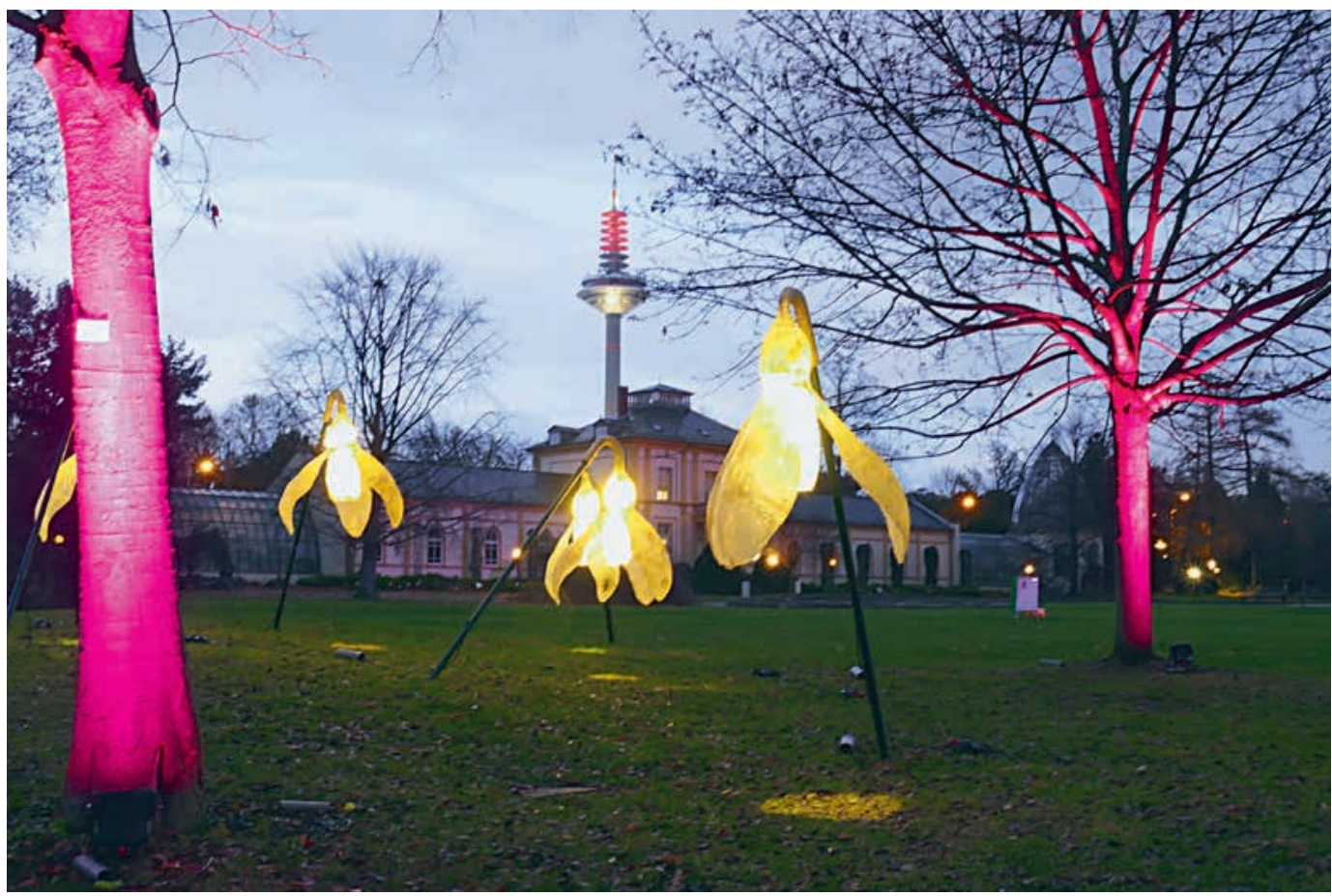

Abb. 2: Die traditionellen Winterlichter-Schneeglöckchen haben einen neuen Standort auf der Spielwiese gefunden. (Foto: H. STEINecke) 


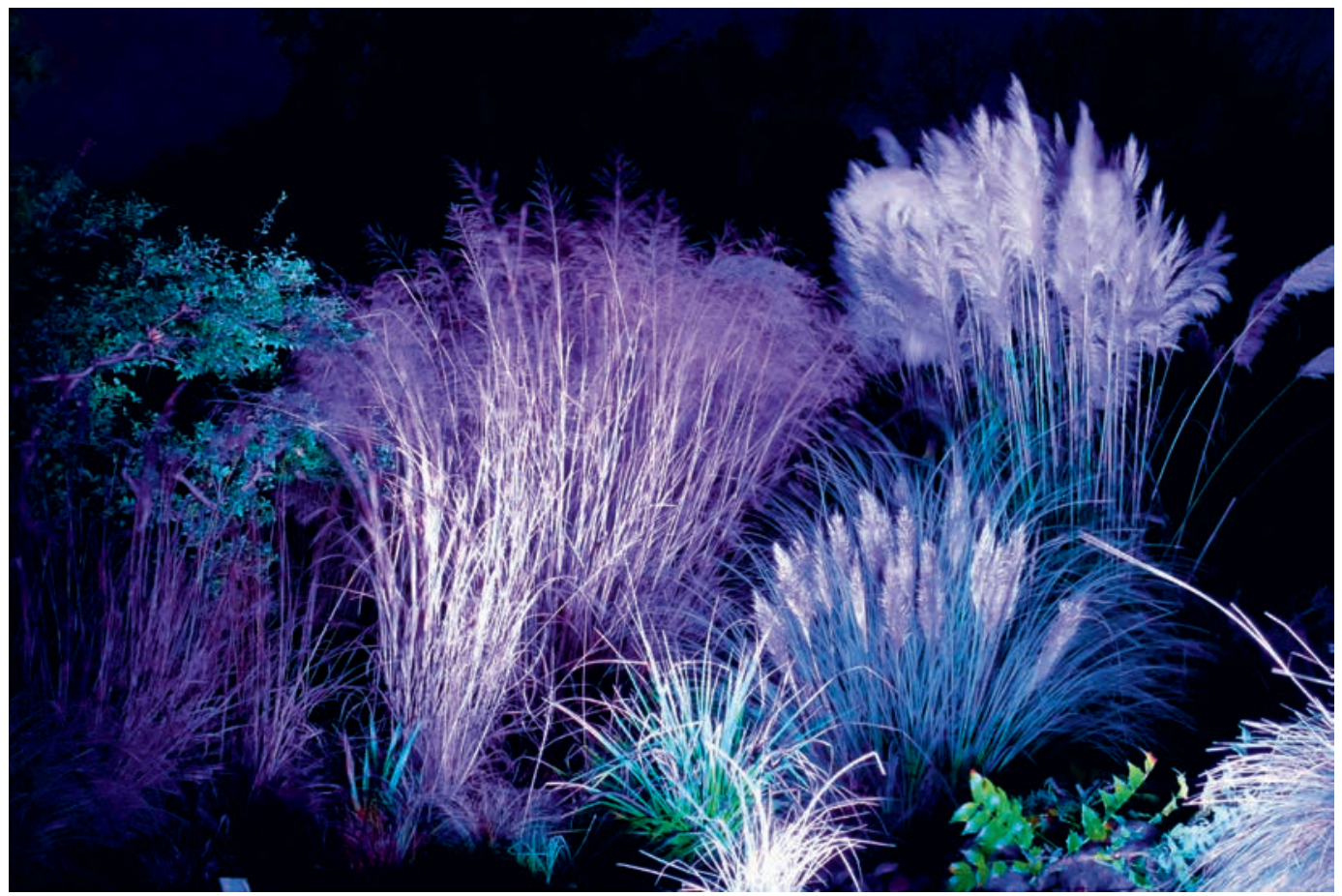

Abb. 3: Wie mit Raureif überzogen wirkt der illuminierte Gräsergarten. (Foto: H. STEInecke)

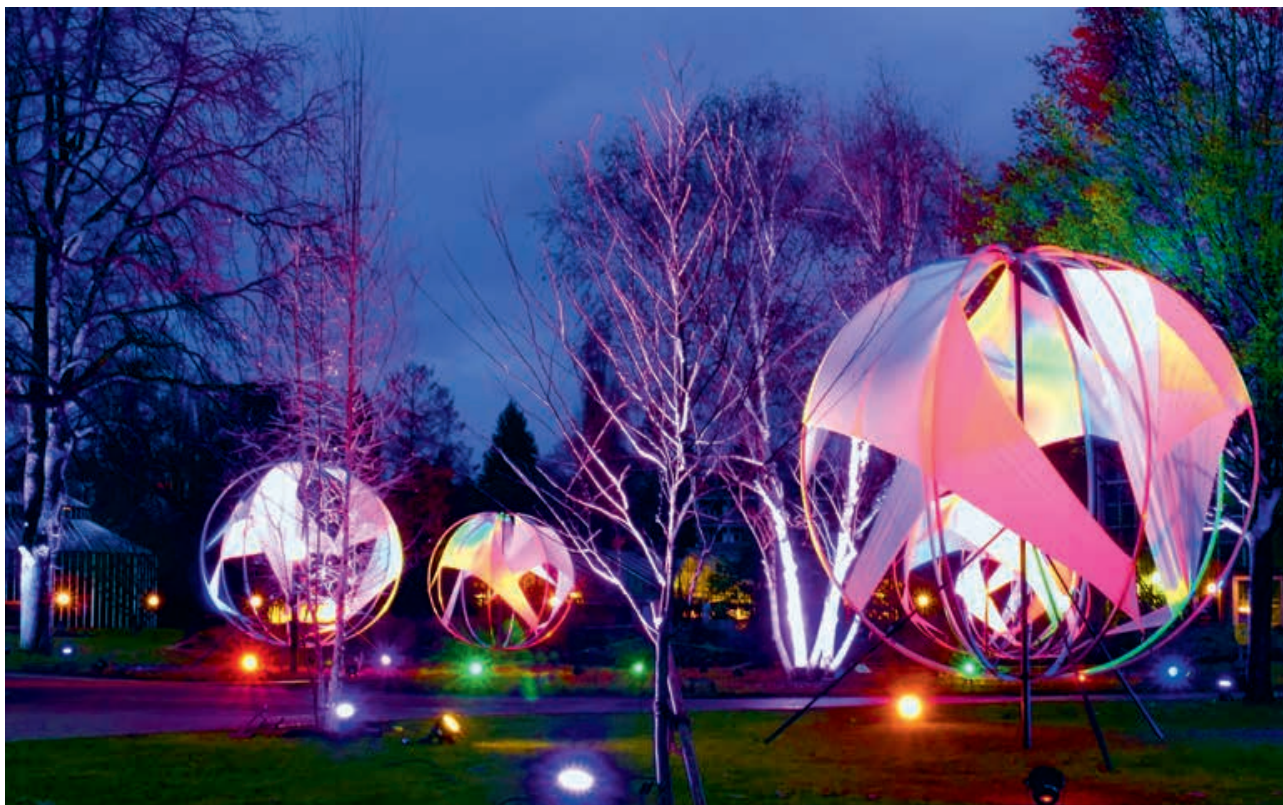

Abb. 4: Drei der fünf mit Stretch-Stoff bespannten Kugeln der Installation „Die fünf Kontinente“. (Foto: H. STEINECKE) 